\title{
A meretrix plautina
}

\section{Caroline Barbosa Faria Ferreira*}

Resumo: Nesse artigo trataremos de uma das principais meretrizes do teatro plautino, Adelphasium, da peça Poenulus, a fim de observar como essa personagem é construída pelo autor. Para tanto, analisaremos o discurso da meretriz e também as falas de outras personagens que se referem a ela.

Palavras-chave:

Plauto;

Meretriz;

Poenulus,

Teatro.

Riassunto: In questo articolo pretendiamo analizzare una delle

Parole-chiave:

principali prostitute del teatro di Plauto, Adelphasium, personaggio

Plauto;

della commedia Poenulus. Osserveremo come questo personaggio è

Prostituta;

construito dall'autore attraverso le battute della prostituta e anche

Poenulus,

degli altri personaggi che si riferiscono a lei.

Teatro.

\footnotetext{
* Mestra pelo Programa de Pós-graduação em Letras da Universidade Federal do Espírito Santo.
} 


\section{Introdução}

A personagem da meretriz aparece em número bastante expressivo nas comédias de Plauto. George E. Duckworth (1994, p. 258) divide as meretrices plautinas em duas categorias: 1) aquelas que são inteligentes, experientes, mercenárias e sem sentimentos, dispostas a arruinarem os filhos de famílias abastadas e os velhos libidinosos para alcançarem seus objetivos. Preferem antes o dinheiro que o amor, pois o dinheiro é o fator determinante para que os seus favores sejam alcançados; e, 2) jovens apaixonadas, fiéis aos seus amantes, que normalmente não se entregam a outros homens por interesse.

Dentre as meretrices interesseiras, as principais representantes são Phronesium, de Truculentus, Erotium, de Menaechmi e as irmãs Bacchis, de Bacchides. Plauto descreve com frequência os subterfúgios que essas meretrizes utilizavam para obter presentes de seus amantes. Às vezes, através de reclamações, estas obtinham casas ou propriedades de jovens ingênuos.

No segundo grupo, temos as apaixonadas meretrizes Selenium, de Cistellaria, Philocomasium, de Miles Gloriosus, Philaenium, de Asinaria e Philematium de Mostellaria como principais representantes. Essas personagens normalmente sofrem durante toda a peça grande oposição do leno ou da lena para poder concretizar o seu amor

Acerca dessa diferenciação no caráter da meretrix plautina, Anne Duncan (apud FARAONE; MCCLURE, 2006, p. 257) afirma que a boa e sincera meretrix é uma pseudohetaira, uma menina que, apesar de ocupar a posição de meretriz momentaneamente, ao fim da peça descobre ser uma cidadã, e se casa com o jovem por quem está apaixonada. Segundo a autora, a verdadeira meretrix plautina, que é semelhante à hetaira na comédia nova grega, é aquela que tem um mau caráter. Sobre as primeiras, Duckworth (1994, p. 259) afirma que as prostitutas que são apaixonadas por algum jovem são muito mais simpáticas e compreensivas, embora Plauto enfatize em suas peças muito mais o humor e a inteligência do que as boas ações dessas personagens. $O$ termo "meretrix". para o autor, é talvez mal justificado, já que as jovens estão vivendo com o homem de sua escolha. Meninas como Selenium, Philaenium e Philematium, expressam o seu amor e lealdade por um homem e resistem aos conselhos de mulheres 
mais experientes que dizem que elas devem estar preocupadas apenas com o dinheiro e não devem se apaixonar por ninguém. ${ }^{1}$

As meretrices de Plauto podem ainda ser livres de nascimento, libertas ou escravas. Segue abaixo o quadro com a classificação das meretrices encontradas nas peças plautinas. ${ }^{2}$ Cumpre antes salientar que, ao categorizarmos esta personagem, observamos que, além das meretrizes indiferentes - não apresentam características específicas -, há uma meretriz que não se encaixa em nenhuma dessas categorias, a meretrix Adelphasium. Classificamos essa personagem como inconstante, visto que, ao longo da peça, ela apresenta características da meretriz interesseira e da meretriz apaixonada.

\section{Quadro 1:}

INTERESSEIRAS APAIXONADAS INDIFERENTES INCONSTANTES

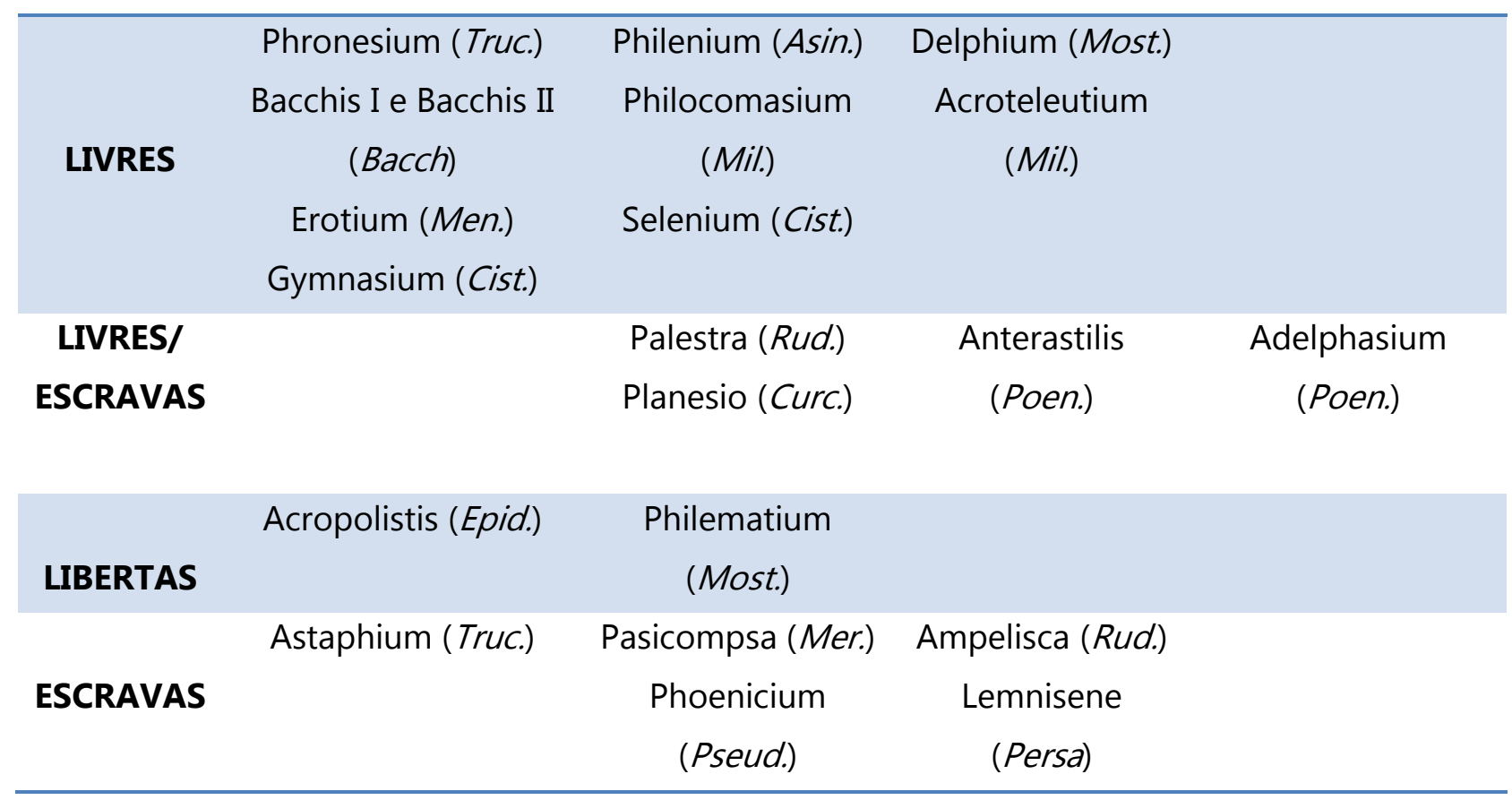

Dada a brevidade desse artigo, nos ateremos apenas à análise da meretriz Adelphasium. A fim de caracterizarmos a personagem, analisaremos principalmente as falas sobre si mesma e, também, sobre outras meretrizes.

\footnotetext{
${ }^{1}$ Sobre esta questão cf. Cist. ,78-88; Asin., 537-542; Most., 214, ss.

${ }^{2}$ Neste quadro, optamos por deixar de fora as lenas que aparecem nas peças de Plauto, não obstante sabermos que estas personagens são também meretrizes, que, por sua idade avançada, vivem da exploração de meretrizes jovens e inexperientes.
} 


\title{
A construção da personagem Adelphasium, na peça Poenulus
}

A comédia Poenulus, junto com Rudens, é a segunda mais longa peça de Plauto, depois de Miles Gloriosus. A peça tem 1422 versos e um dos motivos para a sua extensão é que ela chegou até nós com duas cenas finais.

Segundo Perna (1954, p. 67), não se pode ter uma datação segura da primeira representação da peça. Hueffner (1894 apud PERNA, 1954, p. 57) e Michaut (1920) sugerem a data de 194 a.C., isto é, logo após a guerra vitoriosa conduzida por Flamínio e pelo rei Eumene contra Nabide, tirano de Esparta. Segundo esses autores, seriam uma alusão desse fato os versos 661-666 da peça, mas esta alusão é muito discutível para alguns estudiosos. Do modelo utilizado por Plauto para escrever a peça, a personagem Prologus afirma:

\author{
Carchedonius uocatur haec comoedia: \\ Latine Plautus patruos Pultiphagonides. (Poen., 53-54) \\ Esta comédia em grego se intitula Carchedonius, \\ em latim Plauto a intitulou Pultiphagonides. ${ }^{3}$
}

Não se sabe exatamente quem escreveu a peça grega utilizada como modelo para Poenulus, mas alguns estudiosos acreditam que Carchedonius foi escrita por Menandro, não obstante essa opinião não ser unânime. ${ }^{4}$

Poenulus tem treze personagens: as irmãs meretrizes (Anterastilis e Adelphasium), o jovem apaixonado (Agorastocles), o escravo de Agorastocles (Milphio), o leno (Lycus), o soldado que compra Anterastilis (Antamoenides), as testemunhas (sem nome), o capataz de Agorastocles (Collybiscus), o escravo de Lycus (Syncerastus), o cartaginês, pai das jovens meretrizes (Hanno), a ama das meretrizes (Giddenis), um jovem escravo e uma escrava (sem nome).

Poenulus é uma das comédias mais problemáticas de Plauto. Algumas inconsistências têm levado os estudiosos a concluir que o texto da peça que chegou até nós representa uma mistura irregular de diversas comédias gregas. Muitas foram as tentativas para identificar as fontes de Plauto; a crença de que a peça representa uma contaminação de várias comédias gregas foi finalmente questionada por Fraenkel em

\footnotetext{
${ }^{3}$ As traduções dos trechos latinos são de nossa autoria.

${ }^{4}$ Dentre eles estão J.Geffcken (1898, p. 5), Studien zu Menander e Michaut (1920, p. 124), Plaute.
} 
1922. ${ }^{5}$ Ele afirmou que Plauto adicionara somente uma cena $(\mathrm{I}, 2)$ de uma segunda comédia grega no original que ele utilizou para compor a peça (FRAENKEL, 2007, p. 143).

Nesta cena, o adulescens Agorastocles e seu escravo Milphio escutam escondidos uma conversa entre Adelphasium e sua irmã Anterastilis. Fraenkel exclui esta cena do original grego porque ela serve somente para sublinhar o caráter das jovens sem avançar o enredo da comédia. Ele acreditava que o propósito desta cena era o de enriquecer a peça (FRAENKEL, 2007, p. 149).

Em exame mais acurado desta cena, podemos observar algumas referências a eventos contemporâneos a Plauto. Isto sugere que, ainda que ela não tenha sido inventada por Plauto, foi habilmente adaptada para o contexto romano, pois faz referência a algumas questões do período em que a peça foi produzida, logo após o fim da Segunda Guerra Púnica. Patrícia Johnston (1980, p. 144) afirma que está neste fato uma pista para muito do humor da peça, humor que teria sido perdido pela distância de muitos séculos, mas que seria evidente para o público plautino.

Há na peça uma acumulação de elementos que contribuem para o enlace final. Primeiro Agorastocles é sequestrado quando criança e levado a Calidon; depois as meninas, filhas de Hanno e primas de Agorastocles também são sequestradas, e levadas pelo o leno que as comprou para Calidon, por motivo de negócios; o pai das jovens e tio de Agorastocles também vai até Calidon procurar suas filhas, sem saber que ali acharia, além das meninas, o seu sobrinho perdido. O homem que adotou Agorastocles, e que o fez seu herdeiro, era amigo de seu tio, e por isso, quando Hanno chega à cidade, vai diretamente para a casa do jovem. E a chegada de Hanno na véspera da Afrodísia, quando as meninas, irrevogavelmente, começariam a ser comercializadas, é certamente, cronometrada.

Outra questão interessante na peça é que nenhuma das dramatis personae é cidadã natural do lugar em que se passa a comédia. Agorastocles nasceu em Cartago, foi escravizado e agora é um cidadão por adoção; Milphio e Syncerastus são escravos, portanto não são cidadãos; Lycus veio de Anactório e é também um forasteiro; o soldado Antamoenides é um forasteiro de origem desconhecida; as testemunhas reivindicam seu direito de livres por terem comprado a sua liberdade, mas esta não

\footnotetext{
${ }^{5}$ A primeira edição do livro Plautinisches im Plautus foi publicada na Alemanha em 1922. Neste trabalho utilizamos a primeira edição em língua inglesa, publicada em 2007.
} 
traria automaticamente a cidadania na comunidade grega; e também as jovens meretrices, assim como Hanno, eram de Cartago.

Logo no início da peça, Agorastocles anuncia duas coisas: que ele ama a mais velha das meretrices (155), e que ela tem um leno mau (157), para que assim fique claro que ele não pode, até aquele momento, tocar nela. Agorastocles diz ao escravo que quer ir ao templo de Vênus para poder se deleitar com a elegância das meretrices (oculos uolo meos delectare munditiis meretriciis, 192). ${ }^{6}$

As próximas a aparecerem na peça são as meretrices, recentemente lavadas e adornadas. Elas estão de saída e tudo foi preparado para a propiciação aos deuses (251256). Sem saber que são observadas por Agorastocles e por seu escravo, as jovens podem conversar despreocupadas. A primeira coisa que Adelphasium faz quando entra em cena é criticar a atenção e as despesas dispensadas à aparência das mulheres. Um homem que quer ter problemas deve adquirir para si um navio e uma mulher, porque as duas coisas lhe causarão muitos problemas (negoti sibi qui uolet uim parare, nauem et mulierem haec duo comparato, nam nullae magis res duae plus negoti habent, forte si occeperis exornare, neque umquam sat istae duae res ornantur neque is ulla ornandi satis satietas est, 210-215). ${ }^{7}$ Desde o momento em que as mulheres acordam, elas nunca param de banhar-se, esfregar-se, limpar-se e secar-se, ou polir, alisar, pintar (219225).

Verifica-se um diálogo entre as irmãs que destaca o bom senso de Adelphasium e a superficialidade de Anterastilis. Quando Anterastilis fala à irmã mais velha sobre a necessidade de estarem belas para que as outras meretrices pudessem invejá-las, ela se apresenta como um modelo de reserva e de honradez. Anterastilis diz a sua irmã:

Satis nunc lepide ornatam credo, soror, te tibi uiderier, Sed ubi exempla conferentur meretricum aliarum, ibi tibi Erit cordolium, siquam ornatam melius forte aspexeris. (Poen., 296-298)

Creio, irmã, que agora você parece estar ornada com bastante elegância, mas quando eles forem comparados aos modelos das outras meretrizes, nesta ocasião, você terá um pesar, se, por acaso, dirigir os olhos para alguém mais bem ornada.

\footnotetext{
${ }^{6}$ Eu quero que os meus olhos se deleitem com os adornos das meretrizes.

${ }^{7}$ Quem quer procurar dificuldades para si, obtenha estas duas coisas, um navio e uma mulher, pois nada traz mais problemas do que as duas coisas, se por acaso começou a orná-las, são duas coisas que nunca terminam de serem ornadas suficientemente, nem estão satisfeitas o bastante com os ornamentos.
} 
A resposta de Adelphasium é exemplar, pois rejeita a inveja e põe o bom caráter acima de qualquer ornamento:

Inuidia in me numquam innatast neque malitia, mea soror. Bono me $\langle d\rangle$ esse ingenio ornatam quam auro multo mauolo: Aurum, id fortuna inuenitur, natura ingenium bonum. Bonam ego quam beatam me esse nimio dici mauolo. Meretricem pudorem gerere magis decet quam purpuram. Magisque meretricem pudorem quam aurum gerere condecet. Pulchrum ornatum turpes mores peius caeno conlinunt, Lepidi mores turpem ornatum facile factis comprobant. (Poen., 299-307)

Nem inveja, nem malícia nunca nasceu em mim, minha irmã. Prefiro ser ornada com uma boa natureza do que com muito ouro: o ouro, pela boa sorte é adquirido, a boa natureza é de nascimento. Eu prefiro ser chamada de boa do que de muito rica. É mais conveniente uma meretriz que tem pudor do que púrpura. E é mais descente uma meretriz que tem pudor do que ouro. Os feios costumes sujam mais do que lama o belo ornamento, os custumes graciosos justificam facilmente um adereço descuidado através de ações.

Anterastilis quer ir logo ao templo de Vênus, mas vê seu desejo adiado, primeiro pelo deliberado atraso de Adelphasium. Quando ela tenta apressar a irmã, Adelphasium, com o discurso de uma meretrix experiente, que não quer ser confundida com uma proseda, prostituta de segunda, repreende a irmã:

Maneat pol. Mane,

Turbast nunc apud aram. an te ibi uis inter istas versarier Prosedas, pistorum amicas, reliquias alicarias, Miseras schoeno delibutas servolicolas sordidas, Quae tibi olant stabulum statumque, sellam et sessibulum merum, Quas adeo hau quisquam umquam liber tetigit neque duxit domum, Seruolorum sordidulorum scorta diobolaria? (Poen., 263-270)

Por Pólux, que espere! Espere. Agora tem muita gente junto ao altar. Você quer estar junto dessas prostitutas comuns, amantes de padeiros, esses restos de alicária, míseras com perfume ordinário, prostitutas ordinárias, cheias de sujeira, que exalam um cheiro de estábulo e de feira, e mera sela e cadeira furada, que jamais nenhum homem livre chegou a tocar nem levá-las para casa, prostitutas velhas que os mais fedorentos escravos conseguem com dois óbolos. 
É interessante ainda notar o modo pelo qual o escravo Milphio se refere à meretrix, ao ouvir a forma depreciativa com que ela se referia aos escravos. Ele diz:

I in malam crucem. tun audes etiam servos spernere, Propudium? quasi bella sit, quasi eampse reges ductitent, Monstrum mulieris: tantilla tanta uerba funditat, Quoius ego nebulai cyatho septem noctes non emam. (Poen., 271-274)

Vai se enforcar! Acaso você tem a audácia ainda agora de desprezar os escravos, infame? Como se fosse maravilhosa, ou como se reis a estivessem contratando, monstro de mulher: tão pouca coisa e dizendo tais palavras. Eu não pagaria nem um copo de neve para passar sete noites com ela.

Chama-nos a atenção o fato de um escravo referir-se a uma mulher livre Adelphasium é livre por nascimento e de família nobre - como se ela fosse uma meretrix escrava ou liberta, pois os escravos plautinos normalmente não se referem às meretrices de livre nascimento com palavras pejorativas. Estes escravos, de modo geral, são aqueles que ajudam as jovens de origem nobres, as pseudo-hetaeras, a encontrarem as suas famílias no final da peça. O escravo comporta-se de forma semelhante ao escravo Cyamus em relação à Phronesium, que não tem a sua origem especificada na peça.

Observando Adelphasium, podemos perceber nela uma característica peculiar, quando comparada às demais meretrices de Plauto: ela não ocupa uma posição fixa na peça quanto ao seu caráter - interesseira ou apaixonada. Suas falas, ora expressam características de uma jovem inocente que se prostitui somente por ser obrigada, ora parecem ser de uma meretrix experiente que só se interessa pelo dinheiro dos seus clientes, como vemos nas falas aqui analisadas.

Agorastocles decide se aproximar das duas jovens e pergunta a elas aonde vão (334). Adelphasium fala que ela está indo ao templo de Vênus, para alcançar o seu favor, pelo que o seu admirador retruca que Vênus já está bem propícia a ela. Então Adelphasium diz que haverá um mercado de mulheres, e que ela pretende se mostrar nele (quia apud eadem Veneris hodiest mercatus meretricius: eo conueniunt mercatores, ib ego me ostendi uolo, 339-340). ${ }^{8}$

\footnotetext{
${ }^{8}$ Porque hoje, no templo de Vênus, é o comércio de meretrizes: os mercadores se encontram ali, e nesse lugar eu quero me mostrar.
} 
Podemos perceber ainda que Adelphasium refere-se a si mesma e às outras meretrices como se fossem mercadorias. Ela afirma que, como em um mercado, elas se expõem no templo de Vênus para serem compradas pelos mercadores. Nota-se, através de sua fala, que ela se exibirá no templo não por ser obrigada pelo leno, mas sim porque quer ser escolhida por bons clientes.

Em vários momentos da peça, o ethos interesseiro da meretrix é construído através de suas falas e de seu comportamento. Em outras ocasiões, porém, Adelphasium se apresenta como uma jovem de nobre caráter, que vive como uma meretrix somente porque é obrigada a fazer a vontade de seu leno. Quando Agorastocles quer tocá-la, ela afirma ao jovem: "pura sou, por favor, me toque menos, Agorastocles" (pura sum, comperce amabo me attrectare, Agorastocles, 350).

E quando o jovem pergunta a Adelphasium quando ela irá a sua casa, ela lhe responde com bastante aspereza: "no dia em que o Orco despachar os mortos do Aqueronte" (quo die Orcus Accherunte mortos aamiserit, 344). Ela o rejeita, mas quando ele fala sobre o dinheiro que tinha em casa, ela parece estar muito mais receptiva para a sua oferta (345-346).

Através de suas falas, podemos perceber que a meretrix não é apaixonada por Agorastocles, mas aproveita-se de seu amor para conseguir a liberdade almejada. Ela não deixa de reprová-lo pela sua incapacidade de cumprir sua promessa de libertá-la:

Non aequos in me es; sed morare et male facis. Bene promittis multa ex multis: omnia incassum cadunt. Liberare iurauisti me haud semel, sed centiens: Dum te expecto, neque ego usquam aliam mihi paraui copiam Neque istuc usquam apparet; ita nunc seruio nihilo minus. I, soror. Abscede tu a me. (Poen., 359-363)

Você não é justo comigo, mas me estorva e me faz mal. Você me prometeu muito: todas as promessas se perdem. Jurou que me libertaria, não apenas uma vez, mas cem. Durante o tempo que espero você, nem eu arranjei outro recurso para mim, nem isso aparece. Assim, agora sou uma escrava de nenhum valor. Venha, irmã. E você, fique longe de mim.

Cumpre salientar que as irmãs passam quase toda a peça sem se referirem ao seu nascimento livre, não obstante o público ser informado, ainda no prólogo, sobre os fatos ocorridos. Somente na primeira cena do quarto ato, depois que o leno já tinha 
sido enganado por Agorastocles e Milphio, é que uma personagem menciona o fato na peça. $O$ escravo Syncerastus entra em cena para falar ao escravo Milphio que as garotas eram cidadãs cartaginesas que tinham sido roubadas quando crianças (894-900). E Milphio sai do palco para levar as novas a Agorastocles.

Hanno aparece na peça no quinto ato, e depois de muitas peripécias, descobre que seu sobrinho e suas filhas estão no mesmo lugar em que ele se encontra. Sua alegria, que já é grande, será completada com o retorno das meninas do templo de Vênus (ato 5, cena 4), triunfantes com o sucesso de seu sacrifício, pelos bons augúrios dos deuses e pelo completo esplendor da ocasião (1174-1195). Porém depois de uma fala de Anterastilis, Adelphasium tem mais um súbito ataque de respeitabilidade. Ela diz a Anterastilis que ela era mais insensata do que ela gostaria que fosse (stulta, soror, magis es quam uolo, 1194). ${ }^{9} \mathrm{E}$ ainda afirma que mesmo elas sendo escravas, não estariam bem, por causa da família da qual elas procediam, se se comportassem de forma a provocar o escárnio das outras pessoas. E diz ainda que as mulheres têm muitos defeitos, mas o maior é o de estarem muito contentes de si mesmas ao invés de pensarem em como contentar os homens. (non eo genere sumus prognatae, tametsi sumus seruae, soror, ut deceat nos facere quicquam quod homo quisquam inrideat. Multa sunt mulierum uitia: sed hoc e multis maxumumst, quom sib nimis placenta minusque addunt operam uti placeant uiris, 201-204). ${ }^{10}$

Antes das jovens deixarem o palco, se dirigindo para a casa do leno, depois de falarem mais uma vez sobre os bons presságios dos deuses, Hanno as chama. Agorastocles fala com as jovens como se o pai delas fosse um benfeitor que quisesse tê-las para si. Sem saber que aquele homem era seu pai, quando ele diz que seria para elas motivo de grande alegria (117) Adelphasium diz que ela e sua irmã lhe recompensariam: (at edepol nos uoluptati tibi, 1218). Então, acontece a tradicional cena de reconhecimento na comédia, o leno é punido e Agorastocles obtém a promessa de seu tio de que lhe concederia a permissão para se casar com Adelphasium.

\footnotetext{
9 "Você é mais louca do que eu gostaria".

10 "Irmã, apesar de sermos escravas, não fica bem, pela família que procedemos, fazer qualquer coisa que provoque a ridicularização dos outros. Muitos são os vícios das mulheres, mas este é o pior deles: elas estão muito preocupadas consigo e muito pouco se ocupam com o trabalho de agradar os homens".
} 


\section{Conclusão}

Sobre a suposta contradição no caráter da personagem Adelphasium, muitos críticos afirmam que:

Uma evidente prova da dupla estrutura, de derivação de duas diversas tramas cômicas, seria dada pela evidente contradição que mina o caráter de Adelphasium, que na segunda cena do primeiro ato apareceria com a mentalidade típica de uma cortesã de bordel, enquanto no quinto ato se apresenta com a altura de uma jovem de nobre nascimento, a qual somente a sorte adversa poderia impor uma condição tão dolorosamente inferior a sua origem social (PARATORE, 1992, p. 123).

Paratore, porém, demonstra em sua breve análise que toda a tese de contradição no caráter da meretrix não pode ser confirmada na peça. Ele então comprova, através da observação das falas de Adelphasium, que ela não tem um caráter incoerente. $O$ autor explica que a afirmação de Adelphasium de que iria se oferecer no templo de Vênus (339-340) e também a de que daria prazer ao homem que lhe desse a liberdade (1218) é explicada pelo fato de a jovem querer a todo o custo a sua liberdade, visto que sabia ser de origem nobre. Esta hipótese é confirmada na fala da meretrix a Agorastocles nos versos 359-363. Adelphasium ainda é pura, como ela mesma afirma (1218), porque o leno ainda a conservava para fazer crescer o seu preço, conforme é declarado no prólogo nos versos 98-101. E ainda, sobre a fala da meretrix à sua irmã Anterastilis, Paratore afirma que Adelphasium, como irmã mais velha, tinha a responsabilidade de ensinar bons valores a sua irmã, embora vivessem em um ambiente corrompido em companhia de outras meretrizes (PARATORE, 1992, p. 125-126).

A partir dessa breve análise, podemos concluir que Adelphasium apresenta em si características da meretrix mercenária e cruel, que só se interessa pelo dinheiro de seus clientes, mas também apresenta características da meretrix apaixonada, demonstrando em alguns momentos ser virtuosa e ajuizada.

Dessa forma, Adelphasium estaria muito mais próxima das meretrices terencianas do que das plautinas, visto que aquelas apresentam um caráter diversificado - são mulheres generosas ao longo da peça, mas também se preocupam com o seu sustento e exploram seus clientes. Enquanto as meretrices plautinas apresentam predominantemente um caráter interesseiro ou apaixonado. 


\section{Referências}

\section{Documentação primária impressa}

PLAUTE. Comédies. Texte établi et traduit par Alfred Ernout. Paris: Les Belles Lettres, 1996, t. I-VII.

- A comédia da cestinha. Introdução e versão do latim Aires Pereira do Couto. Coimbra: Festea, 2004.

A comédia da marmita. Introdução, versão e notas de Walter de Medeiros. Brasília, Editora Universidade de Brasília, 1994.

. Comédias. Seleção, introdução, notas e tradução direta do latim por Jaime Bruna. São Paulo: Cultrix, 1980.

. Comédias III. Tradução José Antonio Enríquez González. Madrid: Gredos, 2002.

. Comédias. Tradução de. C. A. Fonseca, A. P. Couto, W. Medeiros, C. Teixeira, H. Toipa. Lisboa: Imprensa Nacional-Casa da Moeda, 2006.

- Estico, de Plauto. Introdução, tradução e notas de Isabella Tardin Cardoso. Campinas: Unicamp, 2006.

. Le tre monete. Tradução de. E. Pasetto. Milão: Carlo Signorelli Editore, 1933.

O Truculento. Introdução tradução e notas Adriano Milho Cordeiro. Coimbra:

Centro de Estudos Clássicos e Humanísticos, 2010.

. Os dois Menecmos. Introdução, versão do latim e notas de Carlos Alberto Louro Fonseca. Coimbra, Instituto Nacional de Investigação Científica, 1983.

. Pseudolo. Prólogo de Arturo Álvarez Hernández. Buenos Aires: Losada, 2005.

- Tutte le commedie. Tradução de Ettore Paratore. Roma: Grandi Tascabili Economici Newton, 1992

PLAUTUS. Comoediae. Recognouit breuique adnotatione critica instruxit W. M. Lindsay. Oxonii, Typographeo Clarendoniano, tomo I-II, 1996.

\section{Obras de apoio}

ADAMS, J. N. The Latin sexual vocabulary. Baltimore, 1982. 
DUPONT, F. Teatro e societá a Roma. Tradução de Giorgia Viano Marogna. Roma-Bari: Laterza, 1995.

DUCKWORTH, G. E. The nature of roman comedy: a study in popular entertainment. University of Oklahoma Press: Norman, 1994.

FARAONE, C. A.; MCCLURE, L. K. Prostitutes \& courtesans in the Ancient World. United States of America: University of Wisconsin System, 2006.

FRAENKEL, E. Plautine elements in Plautus. New York: Oxford University Press, 2007.

GRIMAL, P. O teatro antigo. São Paulo: Martins Fontes, 1978.

GEFFCKEN, J. Studien zu menander. German: Hamburg Lutcke \& Wulff, 1898.

HUNTER, R. L. A comédia nova da Grécia e de Roma. Tradução de Rodrigo Tadeu Gonçalves. Curitiba: Editora da Universidade Federal do Paraná, 2009.

JOHNSTON, P. A. Poenulus I, 2 and Roman women. Transactions of the American Philological Association, v. 110, p. 143-159, 1980.

MICHAUT, G. Histoire de la comédie romaine - Plaute. Paris: Boccard, 1920.

PARATORE, E. Poenulus - Il cartaginesuzzo. In: PLAUTO. Tutte le commedie. Tradução de Ettore Paratore. Roma: Grandi Tascabili Economici Newton, 1992, p. 119-128.

PERNA, R. La originalità di Plauto. Bari: Leonardo da Vinci, 1954.

SALLES, C. Nos submundos da Antiguidade. Tradução de Carlos Nelson Coutinho. São Paulo: Brasiliense, 1982. 